\section{REP ORT S}

\author{
on
}

\section{SANITARY ENGINEERING IN HOUSES, HOSPITALS, AND PUBLIC INSTITUTIONS.}

\author{
B Y W I L L I A E A S I E, C.E.
}

\section{III.-TRAPS AND TRAPPING.}

PERHAPS in the whole history of sanitary matters no article can be found which has more perplexed the British householder than the article known as a trap. Each inventor, vendor, and fitter-up, has lauded such and such a contrivance; and, believing that the artisan knew better than himself, the householder has patronised it, persevered in its use-nay, in some cases, even argued enthusiastically in its favour, although really ignorant of its exact working. Now, it may be taken for granted that more disease is traceable to injudicious draining than to aught else in the way of sanitary neglects. And first of all "in pride of place" amongst the many defaults of drainage, sits what we will term imprudent trapping. How can it be otherwise, when, as is mostly the case, the cesspool is unventilated, the sewer insufficiently so, the house portion of the drain boxed up, and there is no escape for the compressed gases, unless they bubble up through the water contained in the trap? The consequence of this is, that, independently of the suction which the house fires will exert under ordinary circumstances upon the drains, the germs of disease will find their way, with the offensive and other gases, into the very bed-rooms. Honestly speaking, traps are dangerous articles to deal with : they should be treated merely as auxiliaries to a good drainage system. If the house be disconnected from the sewer in any of the ways pointed out in my last article, a trap to all else than the closet might safely be dispensed with. Nevertheless it will be found very convenient to use traps in the sink, the lavatory basin, the bath overflow, and the kitchen waste, if only to prevent the rush of cold air. Some little effluvium may also escape from the portion of the drain on the house side of the disconnection, and other contingencies might arise, where a barrier of water, however slight, would be advisable. I will now indicate the various species of traps which are used in and around buildings, and point out their merits.

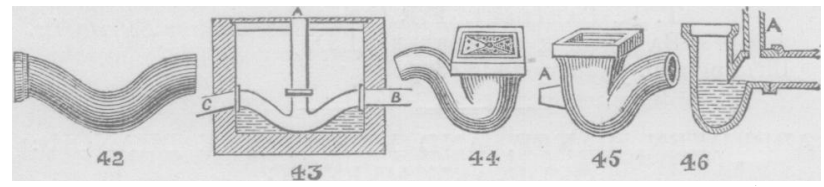

What is called a syphon for insertion in a line of drain-pipes is drawn at fig. 42 ; and this is relied upon to prevent the return of foul gases from a sewer or a cesspool. If properly laid and frequently flushed out, it will be found serviceable ; but, if badly laid, or if it become clogged, it proves very troublesome, and even mischievous. It would be preferable to adopt in all cases the inlet syphon, shown at the lower portion of fig. 43. If the syphon were used just as drawn, with a brick wall surrounding it, the well-hole ventilated, and with an upright pipe rising from its inlet to the ground line, it would form the very best house-drain disconnector. No gas from the pipe (c) which leads to the sewer could enter the house by way of the house-drain (B), because it would be withdrawn by the ventilating pipe (A), which stands over the water-trap inside the syphon.

A sink-trap of pottery ware, on the close syphon principle, is represented at fig. 44, and is found extremely useful, provided the drains are disconnected from the sewer. In certain cases-as, for example, in a laundry-it should have an aperture at the back, in order to connect with a ventilating pipe, leading to the exterior of the house (see fig. 45). The drain would, however, be more effectually ventilated if the effluvium-pipe were fixed perpendicularly over the drain, as at fig. 46 . In the former case the gas is waited for, until it has risen through the trapping water, and in the latter it is withdrawn beforehand.

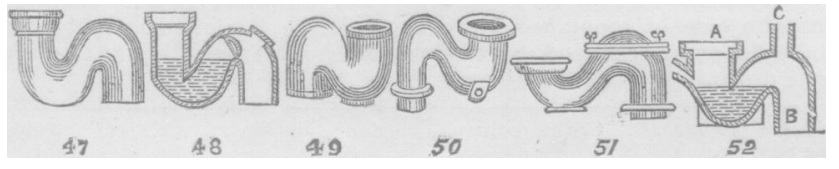

Besides the common, the outlet, and the close syphons, just described, there are S-shaped ones, a few of which it will be necessary to illustrate. The common earthenware closet-syphons are drawn at figs. 47 and 49 ; the former being less compact in shape than the latter. An iron trap of the same construction is given at fig. 50 ; but, unless properly enamelled, this is not such a cleanly article as the glazed earthenware syphon. The above class of traps will work very satisfactorily, provided that the soil-pipe is efficiently ventilated. A refinement in the shape of an access, with cover situated at the highest point of the sigmoid, is exhibited at fig. 5 I. This pattern is intended for more effectually removing obstructions, and for the better cleansing of the trap. It is a desideratum, but it is one very difficult to obtain upon an earthen-ware syphon. On an iron one, as may be noticed at fig. $5 \mathrm{I}$, a good screw with proper packing would replace a light cover, which could not be screwed firmly down, and which would have to rely upon cement or other luting.

Fig. 52 represents Dr. Taylor's syphon-trap-that which is used in his closet-pan, and it embodies all the requirements of modern times. The pan of the closet, which is fitted into the socket (A), is ventilated by a pipe, which joins the ventilating pipe (C), and goes up to the roof. A two-inch supply-pipe from the cistern divides behind the closet-pan, and one moiety enters the pan above the opening (A), whilst the other enters the syphon-trap under the opening (A) through the inclined channel. These two streams of water act simultaneously when the water-valve is raised, and scour out both the pan and the trap beneath down the pipe ( $B$ ) into the drain. Apart from the value of this improved syphon as a closet-fitting, its use as a large ventilated sink or other trap must be obvious.

The design, fig. 48 , represents a sink syphon-trap, with a flap-trap, or rather valve, inside, by which it is intended to prevent the sewer-air from entering a building. If a partial vacuum arose in the sewer, the valve would open sewerwards and establish an equilibrium, but the sewer-air could not pass into the house, unless at the moment when the waste-water of the sink was rushing through the opened valve to the drain below. A proper ventilation of the sewer would render such a complicated arrangement quite useless.

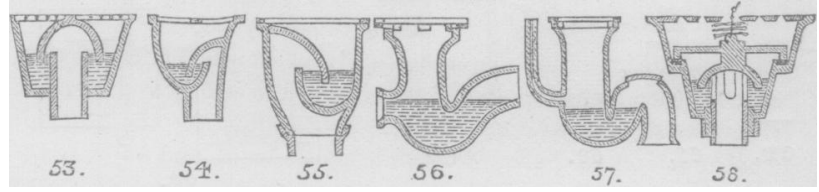

Proceeding now to the kitchen or scullery sink-traps, I illustrate at fig. 53 the common house bell-trap, or, rather, the common domestic air-poisoner. If the majority of houses were inspected at a given hour in the day, the cover with the inverted cup-which when down forms the slight and only trapping-would be found to be taken up by the servants in order that the water should drain nıore quickly away and carry with it the multitudinous scraps of meat and other food-refuse ; or, the cover would be removed because the trap-chamber was filled up with the accumulated grease, and would not work when it was down in its proper place. The result of this uncovering would be that the draingases would rise unobstructedly up through the pipe and disperse over the house. If the house-drain were in direct connection with the sewer, and the latter poorly ventilated, a lighted candle held over the uncovered pipe would be speedily blown out.

One remedy for this state of things would be the substitution of a trap like fig. 54, in which the diaphragm composing the trap is attached to the side of the trap-body. If this cover were lifted up, the trap

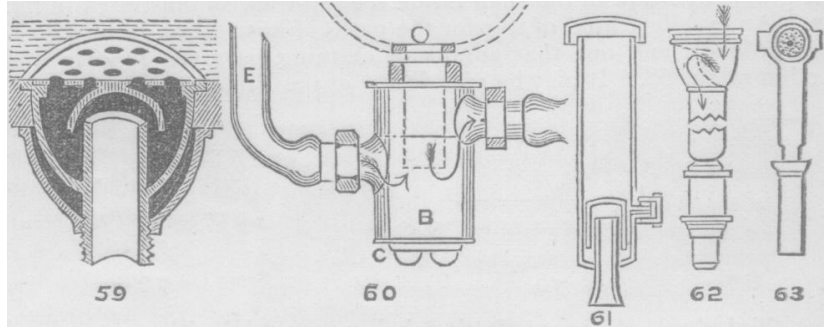

would still retain its hydra ulic seal. An improved form of trap embodying this precaution, and known as the Antill trap, is given at fig. 55 , and a cover which can be locked is placed above it. Another locking grate syphon-trap, known as Tye and Andrews's, is exhibited at fig. 
56. This is more suitable for the sinks of some large establishment, and renders admirable service there. A ventilated syphon sink-trap, with a removable cover to afford inspection and admit of removing obstructions, is drawn at fig. 57 .

What I consider an uselessly complicated sink-trap is exhibited at fig. 58. Here there is a bell-trap at the lottom, and above that again a flange fits flatly on an India-rubber packing, the whole being pressed down from the top, when not in use, by a chain with a pin made to pass through its last link. But, if servants cannot be entrusted with a common bell-trap, of what service would be such a trap as this? The only traps suitable for kitchens and similar places are automatic ones, similar to those drawn at figs. 54 to 57 .

Another class of bell-trap is drawn at fig. 59, and this is a sort which is screwed into the bottom of a bath in order to remove the wastewater. It will not be needful to describe this pattern, as the section sufficiently explains its action. Provided the cover were firmly screwed on, and the drains disconnected and ventilated, there would be little objection to its use ; still, an Antill trap or a proper syphon in the waste-pipe itself would be preferable. The object drawn at fig. 60 is an article intercepting trap, and is indispensable in a butler's sink. The overflow-pipe of the sink or basin is depicted at $\mathbf{E}$, and the wastepipe to drain is shown opposite to it. Should a silver-spoon, for instance, pass down the plug-hole in the basin bottom, it would fall into the water-trap chamber (B), and be recoverable by turning the thumbscrew underneath.

Two traps for the overflow-pipes of a drinking-cistern are drawn at figs. 6I and 62. The former acts partly as a filter, and the latter is merely an adaptation of the Antill trap. They might prevent the influx of cold air into the cistern. No cistern overflow, even with traps affixed, should be soldered into a soil-pipe or waste-pipe of any description, but should be led downwards by a separate pipe and be made to deliver on the ground, or over the disconnecting trap-chamber of the drain, as drawn and explained in a preceding report. Fig. 63 exhibits Lovegrove's air-supply post for the drains, and I figure it here, because it will sometimes be found useful.

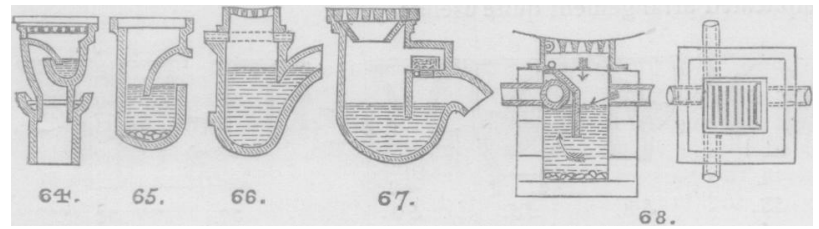

Passing from the interior to the exterior of a house or public building, we enter upon the necessary question of yard-and road-traps. A good trap for a back yard is the large sized Antill trap, drawn at fig. 64. A still larger one, suitable for a court-yard, and one which affords a resting-place for silt or gravel until these are removed, is shown at fig. 65. These two traps would merely have thin cast-iron or earthenware gratings, and would not be useful where there was much traffic. The road gulley-trap (fig. 66), however, is made suitable for building in a paved or flagged roadway, and is sold with a strong dished-out iron grating of the depth of the road foundation. These three traps would ventilate the drain or sewer into the yard or road if the water in them were evaporated, as is sometimes the case in the summer time when the drain or sewer is otherwise unventilated. It might, happen, too, that the surface-water was drained into one common tank, for flushing or gardening purposes, and, if so, bad smells would struggle up to the ground-surface and disperse over the gratings. A cure in such a contingency would be afforded by placing a box of charcoal over the grated aperture in the shelf inside the dip-trap, as illustrated in fig. 67. An excellent kind of trap for the paths of hospital or other recreation grounds, and one that admits of cleaning, is given in plan and section at fig. 68. It may be seen in use at the Brompton Hospital.

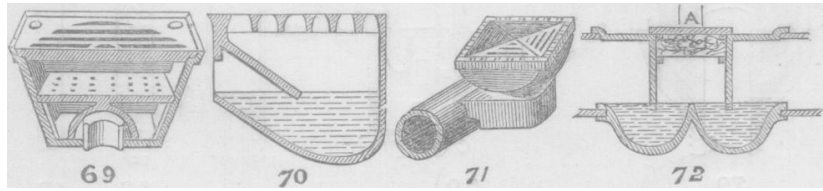

A third form of the everlasting bell-trap, made with an overhead movable grating, and one which is used in stables, is exhibited at fig 69. A ten-inch cast-iron Antill trap, with a wrought-iron perforated cover, would, however, be much better than either this or the special trap, No. 70. Traps of the Antill pattern may be seen at work at the
Brown Institution, London. Where the drainage of a stable runs in closed surface channels inside the stalls and loose boxes, specially constructed horse-pots are rendered necessary, or some such a contrivance as is shown at fig. $7 \mathrm{I}$. A stable-trap, with a disinfecting tray over a double syphon chamber, is drawn at fig. 72 , and is highly efficient. If kept well flushed with water, the ammoniacal and other gases from the drains could never escape to taint the atmosphere of the stable or cowhouse, but would be led off by the ventilating pipe (A).

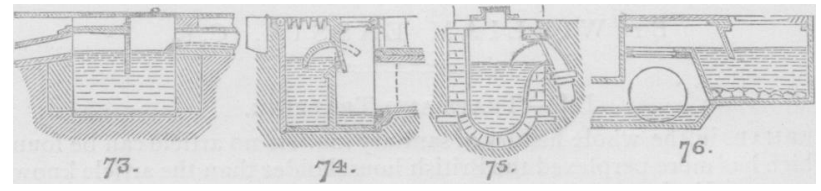

There remains just a word to be said concerning an improper form of road-trap. Such an article, lately used in Edinburgh, is drawn at fig. 73. There is little or no ventilation, and too much evaporating surface.

Fig. 74 exhibits an improved road-trap, with a valve or flap inside, and with half its area (on plan) fitted up with a hinged access plate. A road gully-trap, on the reciprocal ventilating system mentioned in the letter-press to fig. 48 , is given at fig. 75 . The last trap I require to figure is the ball valve-trap, seen at fig. 76 . The ball rises up and fits into the overhead circular opening every time the tide rises and fills the lower drain. In ordinary practice, an use for such a contrivance would rarely if ever arise.

The above may be said to represent, eclectically, all the more useful traps. I have examined and engraved elsewhere* some scores of others, but have chosen the foregoing as representative ones, and as likely to fulfil all ordinary requirements. The next paper will contain a list of rules relative to drainage, and to the ventilating of drains and kindred places, which I hope will prove useful.

\section{ASSOCIATION INTELLIGENCE.}

\section{BIRMINGHAM AND MIDLAND COUNTIES BRANCH.}

THE next meeting of this Branch will be held at the Midland Institute, Birmingham, on Thursday, January 9 th, 1873 .

T. H. BARTLEeT, F.R.C.S. $\}$ Honorary Secretarics.

Birmingham, January 2 nd, 1873 .

\section{ABERDEEN, BANFF, AND KINCARDINE BRANCH : ORDINARY MEETING.}

As ordinary general meeting was held in the Music Hall Buildings, Aberdeen, on Wednesday, December 4 th ; Dr. HARVEY in the Chair. Present, fourteen members and two guests.

New Members. - The proposals for admission of ten new members were laid on the table for next meeting, which was fixed for the 8th of January.

Mr. Vincent Jackson's Springreyed Needli and Dr. Aveling's Apparatus for Transfusion of Blood were exhibited by Messrs. De Lessert and A. Ogston.

Sarcoma. - Dr. Dyce DAvidson read a case of tumour of the upper jaw (spindle and giant cells) growing from the infraorbital canal. It was removed by partial excision of the superior maxilla. Drawings, and sections exhibited under the microscope, illustrated Dr. Davidson's paper.

Lipona.-Dr. WRIGHT narrated the case of a man from whose thigh he removed a myxomatous lipoma which had been attached there by a pedicle for many years. The tumour weighed twenty-four ounces.

Diet of Seamen.-Dr. VANs BEsT read a paper on the diet of the seamen in various services of various countries, pointing out the hygienic causes contributing to scurvy, and suggesting means for improvements in the inspection and dieting of seamen.

Spontaneous Version or Evolution.-Dr. BARCLAY (Banff) communicated a case of spontaneous evolution during labour in a multipara, where the pains produced the version, the shoulder receding as the feet came down.

* Healthy Houses. Second edition. London: Simpkin and Co. 1872. Price One Shilling. 